\title{
Avaliação de resíduo de antibiótico em amostras de leite de vacas após a terapia de vacas secas
}

\section{Evaluation of antibiotic residues in milk samples from cows after dry cow therapy}

\author{
Amancio Estevão Neto ${ }^{1 *}$, Felício Garino Júnior ${ }^{2}$, Júlio César de Araújo Santos ${ }^{3}$, \\ Layze Cilmara Alves da Silva², Rodrigo Antônio Torres Matos ${ }^{2}$
}

RESUMO: Neste trabalho objetivou-se avaliar a presença de resíduos de antimicrobianos no leite de animais tratados no período pré-parto. Foram utilizados 47 animais de propriedades leiteiras, oriundas do estado de Rondônia, para tratamentos com antibióticos comerciais antimastíticos específicos para uso em período seco (cloxacilinabenzatina e espiramicina em associação com neomicina) e em lactação (cloridrato de ceftiofur) aos 60 e 30 dias pré-parto, respectivamente, em uma única aplicação. As análises para detecção de resíduos de antimicrobianos foram realizadas com um teste microbiológico comercial Eclipse 50 (ZEU-Inmunotec ${ }^{\oplus}$, Zaragoza). Foi constatada a presença desses em 3,44\% dos animais tratados com cloxacilina, em 12,50\% dos animais tratados com espiramicina associada à neomicina e em $10 \%$ dos animais que receberam cloridrato de ceftiofur. O período para o aproveitamento do leite após a terapia de vacas secas com antibióticos mais indicado foi de 30 dias para antibióticos usados durante a lactaçáo e de 60 dias para tratamento de vacas secas. A ocorrência dos resíduos de antibióticos no leite é um risco para a saúde pública e para a contaminação de produtos lácteos.

PALAVRAS-CHAVE: resíduos; leite; vacas secas.
ABSTRACT: The present study aimed to assess antibiotic residues in milk from animals treated in the pre-term period. A total of 47 animals from dairy farms in Rondônia, Brazil, were used for treatment with commercially available antibiotics especific to the dry period (cloxacillinbenzathine and spiramycin associated to neomycin) and during the lactation period (ceftiofur hydrochloride) at 60 and 30 days after delivery, respectively, in a single application. The detection of antimicrobial residues was performed using the commercial microbiologic kit Eclipse 50 (ZEU-Inmunotec ${ }^{\oplus}$, Zaragoza). The results showed antibiotic residues in $3.44 \%$ of animals treated with cloxacillinbenzathine, in $12.50 \%$ of animals treated with spiramycin/neomycin, and in $10 \%$ of animals treated with ceftiofur hydrochloride. The period indicated for milk consumption after therapy was 30 days for lactation antibiotic products and 60 days for dry cow therapy. The occurrence of the antibiotic residues in milk is a risk to public health and for the contamination of milk products.

KEYWORDS: residues; milk; dry cows.

\footnotetext{
'EMATER - Ji Paraná (RO), Brasil.

${ }^{2}$ Laboratório de Microbiologia, Unidade Acadêmica de Medicina Veterinária, Centro de Saúde e Tecnologia Rural, Universidade Federal de Campina Grande (UFCG) Cidade (PB), Brasil.

${ }^{3}$ Instituto de Pesquisa Agronômica - Sertânia (PE), Brasil.

*Autor correspondente: amancio.estevao@yahoo.com.br

Recebido em: 22/04/2013. Aceito em: 05/10/2014.
} 
O tratamento antibiótico da mastite subclínica durante a lactação não tem sido considerado viável economicamente, apresentando resultados favoráveis apenas quando "blitz" terapia é utilizada contra Streptococcus agalactiae (BLOWEY; EDMONDSON, 2010). Essa baixa eficácia resulta da dificuldade na eliminação de muitas infecçôes, principalmente por Staphylococcus aureus (SEARs, 2008). Entretanto, a terapia de vacas secas no final do período de lactação tem sido atualmente o foco dos programas de controle da mastite subclínica por promover a cura das infecçôes pré-existentes no momento da secagem, além de prevenir a ocorrência de novas infecçôes durante esse período (Внuтto et al., 2011). Da mesma forma, o tratamento em novilhas no pré-parto com produtos para vacas secas tem sido adotado, apresentando eficácia na eliminaçấo de infecçôes intramamárias no final da gestação, bem como na redução da mastite na lactação subsequente (Oliver et al., 2003).

Entretanto, o potencial risco da presença de resíduos de antimicrobianos no leite e a conscientização da segurança do alimento e dos perigos microbiológicos obrigam muitos países a impor penalidades para os produtores de leite quando se tem a presença de substâncias antimicrobianas em quantidades náo permitidas. Consequentemente, se faz necessária a utilização de testes que permitam a identificação de resíduos no leite (Hillerton et al., 1999). A presença de resíduos de antibióticos no leite é um parâmetro importante para a indústria de laticínios pelo impacto no processo de fabricaçáo de derivados, além de representar um risco potencial à saúde do consumidor, sendo crucial o uso racional de antimicrobianos em rebanhos leiteiros (MÁrmore et al., 2005).

Segundo Costa et al. (2000), resíduos de antimicrobianos no leite decorrem principalmente do uso abusivo e inadequado de antibióticos e da não obediência ao período de carência do leite de animais tratados, além da prolongada retenção do medicamento na glândula mamária em alguns animais e da antecipação do parto.

RAIA JR (2001), em estudo realizado no estado de São Paulo em animais tratados por via intramamária e sistêmica, verificou resíduos de substâncias antimicrobianas no leite por um período de tempo superior ao tempo de carência recomendado na bula do antibiótico. Segundo o mesmo autor, a persistência de resíduos no leite pode ainda ser aumentada pela presença de um processo inflamatório na glândula mamária. O período de carência do leite para animais tratados durante a lactaçáo por via intramamária varia entre 3 e 5 dias.
Em animais que foram submetidos à terapia de vaca seca com antimicrobiano, o período preconizado para a utilização do leite é de 60 dias (FAGUndes et al., 2004). Entretanto, estudos evidenciam que o tratamento realizado no intervalo de 45 a 65 dias antes do parto com produtos de vaca seca permite que a maioria das infecçóes seja curada, além de haver tempo suficiente para que os resíduos de antimicrobianos sejam eliminados (Owens et al., 2001; Fagundes et al., 2004).

Neste trabalho objetivou-se pesquisar resíduos de antimicrobianos no leite dos animais tratados no período pré-parto com antimicrobianos intramamários para vacas secas e em lactação.

Foram utilizados 47 animais de propriedades leiteiras, oriundas do estado de Rondônia, para tratamentos com antibióticos comerciais antimastíticos específicos para uso em período seco (cloxacilinabenzatina e espiramicina em associaçáo com neomicina) e em lactação (cloridrato de ceftiofur) aos 60 e 30 dias pré-parto, respectivamente, em uma única aplicação (Tabela 1).

A escolha dos três antimicrobianos para o experimento foi realizada com base na disponibilidade dos produtos no mercado local e pelo relato da utilizaçáo desses para tratamento de mastite clínica durante o período de lactação nos rebanhos estudados.

Para avaliação da presença de resíduos de antibióticos no leite, foram coletadas amostras de leite de todos os quartos mamários $(10 \mathrm{~mL})$ no período de 5 a 10 dias pós-parto em frascos estéreis, sendo encaminhadas sob refrigeração ao laboratório, onde foram utilizadas amostras únicas de $15 \mathrm{~mL}$, compostas por partes iguais das quatro amostras coletadas de tetos individuais de cada um dos 47 animais. As análises para detecção de resíduos de antimicrobianos foram realizadas com um teste microbiológico comercial, Eclipse 50 (ZEUInmunotec ${ }^{\circ}$, Zaragoza). Como forma de prevenir a ocorrência de resultados falso-positivos pela interferência de substâncias antimicrobianas naturais do leite, todas as amostras foram aquecidas a $80^{\circ} \mathrm{C}$ por 5 minutos em banho-maria antes da execução dos testes para detecção de resíduos de antibióticos (RAIA JR, 2001). As análises foram realizadas no Laboratório de Microbiologia do Instituto Nacional de Ciência e Tecnologia (INCT) Plantas Tóxicas do Centro de Saúde e Tecnologia Rural (CSTR) da Universidade Federal de Campina Grande, Patos, Paraíba. Para a análise estatística foi realizada a comparação das proporçóes entre os grupos avaliados, utilizado o teste do qui-quadrado para amostras independentes e o teste

Tabela 1. Total de animais tratados entre 30 e 60 dias pré-parto com três antibióticos diferentes em Rondônia, 2011.

\begin{tabular}{|c|c|c|c|c|c|}
\hline Tratamento & Produto & $\begin{array}{c}\text { Período antes do parto } \\
\text { (dias) }\end{array}$ & $\begin{array}{c}\text { Número de } \\
\text { novilhas }\end{array}$ & Número de vacas & Total \\
\hline T1 & Cloxacilina & 60 & 14 & 15 & 29 \\
\hline $\mathrm{T} 2$ & Ceftiofur & 30 & 4 & 6 & 10 \\
\hline T3 & Espiramicina + neomicina & 60 & 1 & 7 & 8 \\
\hline Total & & & 19 & 28 & 47 \\
\hline
\end{tabular}


de McNemar para amostras relacionadas (ZAR, 1999). O nível de significância adotado foi de $5 \%$ e as análises foram realizadas com o programa Minitab, versão 13.0.

$\mathrm{Na}$ Figura 1 sáo demonstrados os resultados do teste de resíduos de antibióticos em vacas e novilhas do grupo tratamento. Foi constatada a presença de resíduos em 3,44\% dos animais tratados com cloxacilina, em 12,50\% dos tratados com espiramicina associada à neomicina e em $10 \%$ dos animais que receberam cloridrato de ceftiofur. Em relação ao total de animais avaliados, foi verificada a presença de resíduos de antibióticos em 6,38\%. Na comparaçáo entre os grupos avaliados, novilhas, vacas e grupos de tratamentos, náo houve diferença significante $(\mathrm{p}>0,05)$.

Atualmente existem vários métodos de detecção de resíduos de antimicrobianos no leite: teste de inibiçáo de crescimento bacteriano (microbiológico), testes imunológicos e teste de receptores de enzimas. Os testes microbiológicos possuem baixo custo e facilidade de execução, podendo garantir que seja avaliado um maior número de amostras. De acordo com Fagundes (2003), o teste microbiológico representa uma boa opçáo para uso como teste de triagem a campo para detecçáo de resíduos em amostras de leite de animais tratados no período seco.

Os três tratamentos avaliados neste trabalho resultaram numa baixa persistência de resíduos de antibióticos no leite dos animais tratados. Entretanto, foram superiores aos resultados observados por Oliver et al. (1984) em estudo realizado com 186 vacas pertencentes a 5 rebanhos nos Estados Unidos, onde foi avaliada a persistência de resíduos de 5 diferentes antibióticos aprovados para vaca seca, sendo observada a ausência de resíduos no leite em 34 animais tratados com cloxacilinabenzatina durante a secagem e avaliadas 4 dias após o parto. Oliver et al. (1992), avaliando 33 novilhas Jersey tratadas 7 dias antes do parto com cloxacilina e cefapirina sódica (produtos para lactaçâa) e reexaminadas 7 dias após o parto, também constataram a ausência

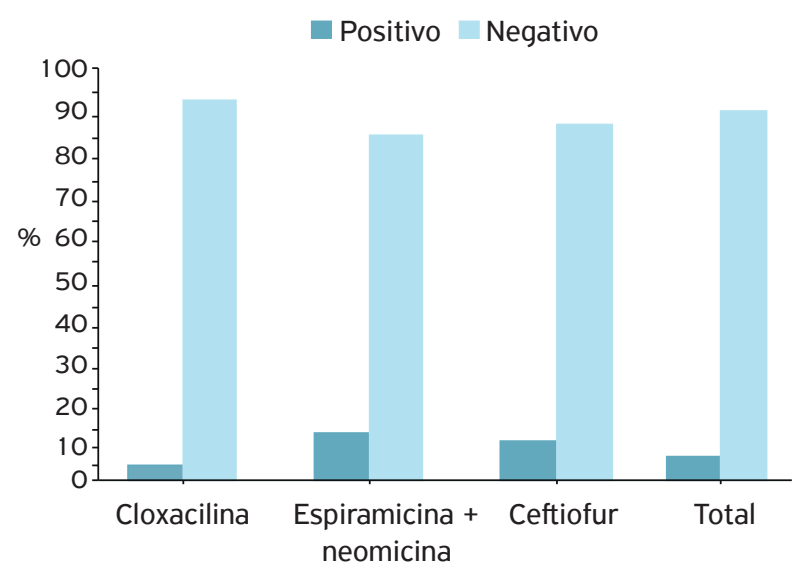

Figura 1. Resultado dos testes de resíduos de antimicrobianos em 47 amostras de leite de 19 novilhas e 28 vacas tratadas no período pré-parto. Rondônia, 2011. de resíduos no leite. No entanto, RAIA JR (2001) observaram uma persistência de resíduos após 65 dias em $28,3 \%$ das vacas tratadas no período seco com um antibiótico aminoglicosídeo (gentamicina), de ação semelhante à neomicina utilizada neste estudo, e em 21,9\% quando uma cefalosporina (cefalônio) foi utilizada, portanto, demonstrando índices superiores aos observados neste experimento. Deve-se ressaltar que a baixa persistência não indica segurança, uma vez que a presença de antimicrobianos no leite traz riscos à saúde pública e prejuízos para a indústria de laticínios, que podem variar de acordo com a concentração deles.

Portanto, o intervalo utilizado entre o tratamento pré-parto e a liberação do leite para o consumo humano sugerido neste estudo com produtos para vacas em lactaçáo e para vacas secas mostra-se vantajoso quando se busca a ausência de substâncias antimicrobiana no leite, corroborando os resultados obtidos por FAGUndes et al. (2004) que, em estudo realizado no estado de São Paulo com tratamento de novilhas no pré-parto, demonstraram que um período de tempo superior a 65 dias foi seguro para o consumo do leite desses animais.

FAGUNDES (2003) avaliou três propriedades no estado de São Paulo sem influência de mastite e/ou infecção da glândula mamária com a ocorrência de resíduos. Foram encontrados percentuais de 17,$98 ; 22,22$ e $26,47 \%$, obtendo-se uma média de positividade de 19,37\%. O autor encontrou percentual de resíduos superiores aos encontrados no presente trabalho. Esses resultados indicam que o tratamento de vacas no momento da secagem pode vir a se tornar um risco, embora esse método de tratamento seja mais eficiente do que a terapia da mastite clínica.

Embora tenha sido observada uma positividade de 6,38\% de resíduos em relaçáo ao total de amostras avaliadas, o período para o aproveitamento do leite, após a terapia de vacas secas com antibióticos, mais indicado foi de 30 dias para antibióticos usados durante a lactação e de 60 dias para tratamento de vacas secas, representando um intervalo de tempo seguro quanto à presença de resíduos no leite. Por outro lado, o tratamento com produtos de lactação nesse intervalo estudado pode resultar em uma baixa persistência do antibiótico na glândula mamária próximo ao parto, comprometendo a eficácia do produto frente às infecçôes intramamárias.

Nas propriedades estudadas, é pratica comum o consumo do leite dos animais de 3 a 5 dias após o parto, fato que aumenta o risco de resíduo de antimicrobiano no leite e, consequentemente, gera risco à saúde dos consumidores e possíveis prejuízos à indústria de laticínios.

A ocorrência de resultados positivos para esse teste deve servir de alerta aos produtores, já que os animais submetidos à terapia de secagem podem estar eliminando resíduos além do período de carência, além do risco desse leite estar sendo incorporado ao tanque de pequena mistura junto ao de animais isentos de resíduos. 


\section{REFERÊNCIAS}

BHUTTO, A.L.; MURRAY, R.D.; WOLDEHIWET, Z. The effect of dry cow therapy and internal teat-sealant on intra-mammary infections during subsequent lactation. Research in Veterinary Science, v.90, n.2, p.316-320, 2011.

BLOWEY, R.W; EDMONDSON, P.W. Mastitis Control in Dairy Herds. 2. ed. Ipswich: Farming Press, 2010. p.194-218.

COSTA, E.O.; RAIA, R.; WATANABE, E.T.; GARINO JR, F.; COELHO, V. Influência do tratamento intramamário de casos de mastite de bovinos em lactação em relação à presença de resíduos de antibióticos no leite dos quartos sadios e tratados. Revista Napgama, v.3, p. 14-17, 2000.

FAGUNDES, H. Ocorrência de resíduos de antimicrobianos utilizados no tratamento de interrupção de lactação no inicio da lactação subsequente em animais com período seco determinado. 2003. $91 \mathrm{f}$. Dissertação (Mestrado em Zootecnia) - Universidade de São Paulo, São Paulo, 2003.

FAGUNDES, H.; GARINO JR, F.; COSTA, E.O. Primi gravid heifers pré-partum: efficacy and antimicrobial milk residue risk. RevistaNapgama, v.7, p.6-12, 2004.

HILLERTON, J.E.; HALLEY, B.I.; NEAVES, P.; ROSE, M.D. Detection of antimicrobial substances in individual cow and quarter milk samples using Devoltest microbial inhibitor tests. Journal of Dairy Science, v.82, n.4, p.704-711, 1999.

MÁRMORE, C.; RAIA, R.; SANTOS, F.G.; PERES, A.A.; MOTA, R.; MELVILLE, P.A.; COSTA, E.O. Influence on Yoghurt production of antibiotic residues and the clinical and subclinical mastitis naturals inhibitors in milk. Revista Napgama, v.8, p.8-13, 2005 .

OLIVER, S.P.; DUBY, R.T.; PRANGE, R.W.; TRITSCHLER, J.P 2nd. Residues in colostrum following antibiotic dry cow therapy. Journal of Dairy Science, v.67, n.12, p.3081-3084, 1984.

OLIVER, S.P.; LEWIS, M.J.; GILLESPIE, B.E.; DOWLEN, H.H. Influence of prepartum antibiotic therapy on intramammary infections in primigravid heifers du ring early lactation. Journal of Dairy Science, v.75, n.2, p.406-414, 1992.

OLIVER, S.P.; LEWIS, M.J.; GILLESPIE, B.E.; DOWLEN, H.H.; JAENICKE, E.C.; ROBERTS, R.K. Prepartum antibiotic treatment of heifers: milk production, milk quality and economic benefit. Journal of Dairy Science, v.86, n.4, p.1187-1193, 2003.

OWENS, W.E.; NICKERSON, S.C.; BODDIE, R.L.; TOMITA, G.M.; RAY, C.H. Prevalence of mastitis in dairy heifers and effectiveness of antibiotic therapy. Journal of Dairy Science, v.84, n.4, p.814-817, 2001.

RAIA JR, R.B. Influência da mastite na ocorrência de resíduos de antimicrobianos no leite. 2001. 87 f. Dissertação (Mestrado) Universidade de São Paulo, São Paulo, 2001.

SEARS, P. Treating subclinical mastitis based on milk culture results. Michigan Dairy Review, v.13, n.3, 2008. Disponível em: <http://www.msu.edu/ mdr/vol 13 no3/vol 13 no3.pdf $>$.Acesso em: 16 mar. 2012.

ZAR, J.H. Biostatistical analysis. 4 ed. Upper Saddle River: Prentice Hall, 1999. 663 p. 